\title{
Body Image and Eating Disorder Symptoms in Sexual Minority Men: A Test and Extension of Objectification Theory
}

\author{
Marcie C. Wiseman and Bonnie Moradi \\ University of Florida
}

\begin{abstract}
On the basis of integrating objectification theory research with research on body image and eating problems among sexual minority men, the present study examined relations among sociocultural and psychological correlates of eating disorder symptoms with a sample of 231 sexual minority men. Results of a path analysis supported tenets of objectification theory with the sample. Specifically, findings were consistent with relations posited in objectification theory among sexual objectification experiences, internalization of cultural standards of attractiveness, body surveillance, body shame, and eating disorder symptoms. Within this set of positive relations, internalization of cultural standards of attractiveness partially mediated the link of sexual objectification experiences with body surveillance; body surveillance partially mediated the relation of internalization with body shame; and body shame partially mediated the relation of body surveillance with eating disorder symptoms. In addition to these relations, internalized homophobia was related to greater eating disorder symptoms through body shame, and recalled childhood harassment for gender nonconformity was linked with eating disorder symptoms through a positive series of relations involving internalization of cultural standards of attractiveness, body surveillance, and body shame.
\end{abstract}

Keywords: gay, bisexual, and sexual minority men, objectification theory, eating disorder, body surveillance, body image

Although eating disorders have been perceived as "women's disorders," men account for approximately $10 \%$ of eating disorder cases (Andersen, 1999; Crosscope-Happel, Hutchins, Getz, \& Hayes, 2000). Sexual minority men in particular may be at heightened risk for eating and body image problems (e.g., Feldman \& Meyer, 2007a; Russell \& Keel, 2002; Siever, 1994). Scholars have speculated about the reasons for higher rates of body image and eating problems in samples of sexual minority men than in samples of heterosexual men, but there is a paucity of theoretically grounded research that identifies sociocultural and psychological correlates of these disparities (e.g., Heffernan, 1994; Lakkis, Ricciardelli, \& Williams, 1999; Siever, 1994). Also, some of the reasons posited for the higher rates of body image and eating problems among gay men-for instance, pressures associated with attracting other men-apply to the broader spectrum of sexual minority men, but this broader spectrum of men is often not considered in this literature. We conceptualize sexual minority men to reflect the continuum of men who view their sexual orientation identity, attraction, or behaviors as something other than exclusively heterosexual; this view avoids binary categorization of gay-heterosexual and gay-bisexual.

Marcie C. Wiseman and Bonnie Moradi, Department of Psychology, University of Florida.

We thank Mary Fukuyama, Carlos Hernandez, Daniel Potazniak, and Jacob van den Berg for their assistance with this project, and we thank Mike Parent for his assistance with preparing this manuscript.

Correspondence concerning this article should be addressed to Bonnie Moradi, Department of Psychology, University of Florida, P.O. Box 112250, Gainesville, FL 32611-2250. E-mail: moradib@ufl.edu
Consistent with calls for counseling psychologists to include diverse populations in eating disorder scholarship (Petrie \& Rogers, 2001; Root, 2001), research is needed to advance understanding of body image and eating problems among sexual minority men. To address the need for theoretically grounded research in this area, we used objectification theory (Fredrickson \& Roberts, 1997) in the present study as a framework for exploring sociocultural and psychological correlates of eating disorder symptoms among sexual minority men. Objectification theory has garnered support in body image and eating disorder research with women; it also has been extended to men in general and to sexual minority men in particular (for a review, see Moradi \& Huang, 2008). Thus, with a sample of sexual minority men, we examined links posited in objectification theory among sexual objectification experiences, internalization of cultural standards of attractiveness, body surveillance, body shame, and eating disorder symptoms. On the basis of prior body image and eating disorder research with sexual minority men (e.g., Beren, 1997; Reilly \& Rudd, 2006), we also explored roles of recalled childhood harassment for gender nonconformity and internalized homophobia within the objectification theory framework.

\section{Body Image and Eating Problems Among Gay Men}

Group comparisons indicate higher levels of body dissatisfaction, concern with weight, and eating problems in samples of gay men than in samples of heterosexual men (e.g., French, Story, Remafedi, Resnick, \& Blum, 1996; Martins, Tiggemann, \& Kirkbride, 2007; Siever, 1994; Strong, Williamson, Netemeyer, \& Geer, 2000). Indeed, levels of body image and eating problems in samples of gay men have been found to be more similar to levels 
in samples of heterosexual women than in samples of heterosexual men (e.g., Beren, Hayden, Wilfley, \& Grilo, 1996; Brand, Rothblum, \& Solomon, 1992; Morrison, Morrison, \& Sager, 2004; Siever, 1994; Strong et al., 2000). In a study of the correlates of eating disorder symptoms among men, Russell and Keel (2002) found that gay sexual orientation accounted for unique variance in eating disorder symptoms beyond that accounted for by overall mental health, suggesting that something unique about gay men's experiences is linked with such symptoms.

Explanations for the prevalence of eating disorder symptoms among gay men have varied over time. Heffernan (1994) observed that some early investigations focused on disturbance in psychosexual development as an explanation for eating disorders among gay men, and findings of such studies were interpreted as evidence of the pathology of same-sex attractions (Heffernan, 1994). But, many of these studies were based on clinical samples of men diagnosed with an eating disorder; such samples may represent the most severe cases due to potential underdiagnosis of eating disorders among men (Crosscope-Happel et al., 2000). Furthermore, in these early studies, gay sexual orientation may have been conflated with sexual orientation conflict because participants often reported conflict with regard to their sexual orientation (Heffernan, 1994). The clinical nature of the samples and potential confounding of gay sexual orientation with sexual orientation conflict may have contributed to the pathologizing view that emerged from early scholarship on eating disorder symptomatology among gay men. Heffernan (1994) pointed out that in contrast to the clinical studies, studies with nonclinical samples highlighted sociocultural factors as potential explanations for eating disorder symptoms among gay men.

Within the literature, sociocultural factors that are thought to promote eating disorder symptoms among sexual minority men include sexual objectification and attractiveness pressures. For example, some authors have posited that men prefer attractive partners more so than do women (Brand et al., 1992; Siever, 1994). For men who want to attract other men (and for heterosexual women), men's greater preference for attractive partners translates into pressure to be attractive in order to attract men. By contrast, heterosexual men (and lesbian women) may experience less pressure in this regard to the extent that their goal is to attract women (Brand et al., 1992; Siever, 1994). Notably, some scholars have pointed to the heightened importance of attractiveness as a factor that shapes eating disorder symptoms among sexual minority men (Siever, 1994; Silberstein, Mishkind, StriegelMoore, Timko, \& Rodin, 1989). In fact, compared with heterosexual men, gay men were found to place more importance on physical appearance in evaluations of themselves and potential partners (Siever, 1994) and have a thinner ideal body type for themselves and their partners (Brand et al., 1992). Such emphasis on partner attractiveness and thinness suggests that sexual minority men who want to attract male partners may experience interpersonal pressure to meet these attractiveness standards. In addition to such interpersonal pressures, analyses of media depictions demonstrate frequent eroticization of men (Rohlinger, 2002) and suggest that sexual minority men may be subtle targets of such sexually objectifying messages (Clark, 1995; Rohlinger, 2002; Sender, 1999).

\section{Objectification Theory}

Evidence of the sexual objectification of sexual minority men suggests the utility of objectification theory for understanding the body image sequelae of these sociocultural pressures. Fredrickson and Roberts (1997) defined sexual objectification as "the experience of being treated as a body (or collection of body parts) valued predominantly for its use to (or consumption by) others" (p. 174). Such experiences (e.g., being the target of sexualized comments or depictions of one's body) reduce a person to her or his body, body parts, or sexual functions and can promote self-objectification or the adoption of an observer's perspective on one's own body (Fredrickson \& Roberts, 1997). Self-objectification is manifested as body surveillance or persistent monitoring of how the body looks (as an object) rather than attending to how it feels or functions. Body surveillance can promote feelings of body shame when the individual evaluates her- or himself against the cultural standard of attractiveness and falls short of that ideal (Fredrickson \& Roberts, 1997). Relations among sexual objectification experiences, internalization of cultural standards of attractiveness, body surveillance, and body shame are posited to promote eating disorder symptoms, and such links are supported in objectification theory research with women (for a review, see Moradi \& Huang, 2008). Specifically, prior data indicate that sexual objectification experiences are linked with greater body shame and eating disorder symptoms through internalization of cultural standards of attractiveness and body surveillance (e.g., Kozee, Tylka, AugustHovarth, \& Denchik, 2007; Moradi, Dirks, \& Matteson, 2005) and that body shame mediates the positive relation of selfobjectification or body surveillance with eating disorder symptoms (Moradi et al., 2005; Noll \& Fredrickson, 1998).

\section{Objectification Theory and Sexual Minority Men}

Although objectification theory research indicates that men and boys (typically presumed heterosexual) report lower levels of self-objectification, body surveillance, and body shame compared with women and girls (e.g., Aubrey, 2006; Lindberg, Grabe, \& Hyde, 2007; Lindberg, Hyde, \& McKinley, 2006; Lowery et al., 2005; McKinley, 1998; Strelan \& Hargreaves, 2005b), the data point to gender similarities in relations among objectification theory constructs and body image and eating problems (e.g., Grabe, Hyde, \& Lindberg, 2007; Hallsworth, Wade, \& Tiggemann, 2005; Lindberg et al., 2007, 2006; McKinley, 1998, 2006; Strelan \& Hargreaves, 2005a) and in the mediating role of body shame in the positive relation of body surveillance with eating disorder symptoms (Tiggemann \& Kuring, 2004). Within this broader objectification theory research with men, a few studies have attended specifically to gay men.

Serpa (2004) found that gay men's average self-objectification, body surveillance, body dissatisfaction, and drive for thinness scores were higher compared with heterosexual men. Also, correlations among self-objectification, body surveillance, and body shame, as well as the correlations of these variables with body dissatisfaction and eating disorder symptoms, were generally stronger and more consistent for gay men than for heterosexual men. Importantly, the pattern of correlations for gay men was consistent with objectification theory; self-objectification, body surveillance, and body shame were correlated positively with each 
other, and body surveillance and body shame were correlated positively with body dissatisfaction and eating disorder symptoms. Martins et al. (2007) replicated these patterns, finding higher levels of self-objectification, body surveillance, body shame, drive for thinness, and dissatisfaction with upper and lower body among gay men than among heterosexual men. They also found that selfobjectification was related to greater body shame for gay men but not for heterosexual men. In addition, body shame mediated the positive links of self-objectification with lower body dissatisfaction and drive for thinness for gay men but not for heterosexual men.

In a separate sample, Martins et al. (2007) experimentally induced a sexually objectifying condition to manipulate the salience of self-objectification. They randomly assigned participants to wear either a speedo (high self-objectification) or a sweater (low self-objectification) in front of a full-length mirror. Men of both sexual orientation groups reported higher body surveillance in the speedo condition than in the sweater condition. But, only gay men reported higher body shame and restricted eating (i.e., ate less snack food in a mock taste test) in the speedo condition than in the sweater condition; heterosexual men in the two conditions did not differ on body shame or restricted eating. The data offered by Serpa (2004) and Martins et al. (2007) suggest that, for gay men, sexually objectifying conditions can produce body surveillance, body shame, and restricted eating. Accordingly, sexual objectification experiences seem important to attend to in evaluating objectification theory with sexual minority men.

In addition to sexual objectification experiences, another experience that may be relevant to understanding sexual minority men's body surveillance, body shame, and eating problems is childhood harassment for gender nonconformity. Specifically, Beren (1997) found that a composite variable that included gay men's recalled experiences of childhood harassment for gender nonconformity (e.g., being teased for not being athletic or masculine enough) was related indirectly to eating disorder symptoms through a series of positive links involving internalized homophobia and feelings of shame. Viewed from an objectification theory lens, childhood harassment for gender nonconformity may function in parallel fashion as sexual objectification experiences. That is, both types of experiences may promote body surveillance, with childhood harassment for gender nonconformity promoting efforts to monitor and reduce gender-nonconforming bodily appearance in order to prevent future harassment. As such, both sexual objectification experiences and childhood harassment for gender nonconformity may promote body surveillance, which, in turn, is linked with greater body shame and eating disorder symptoms.

In addition to the role of recalled childhood harassment for gender nonconformity, Beren (1997) found that internalized homophobia was linked indirectly and positively with eating disorder symptoms through shame. This pattern suggests that within the objectification theory framework, a parallel relation might exist from internalized homophobia to eating disorder symptoms through body-specific shame. In fact, data consistent with this possibility emerged in two other studies with gay men that were not grounded in objectification theory but included constructs similar to those in the theory. Kimmel and Mahalik (2005) found that internalized homophobia was related positively with indicators that paralleled body shame (i.e., body dissatisfaction, distress for failing to meet the masculine body ideal). Similarly, Reilly and Rudd (2006) found that negative attitudes about one's own homosexuality (an indicator of internalized homophobia) were related positively to indicators similar to body shame (i.e., negative view of and dissatisfaction with one's body) but unrelated to a variable similar to body surveillance (i.e., appearance-focused orientation). Thus, internalized homophobia may be related to greater body shame, which, in turn, is linked with greater eating disorder symptoms. Taken together, these findings point to childhood harassment for gender nonconformity and internalized homophobia as potential correlates of body image and eating problems for sexual minority men. In the present study, we explored the roles of these variables within the objectification theory framework.

\section{Overview of the Present Study}

The model examined in this study is depicted in Figure 1. On the basis of prior objectification theory research, positive relations are expected among reported sexual objectification experiences, internalization of cultural standards of attractiveness, body surveillance, body shame, and eating disorder symptoms (Hypothesis 1). Furthermore, sexual objectification experiences are expected to be related to body surveillance through the mediating role of internalization of cultural standards of attractiveness (Hypothesis 2:

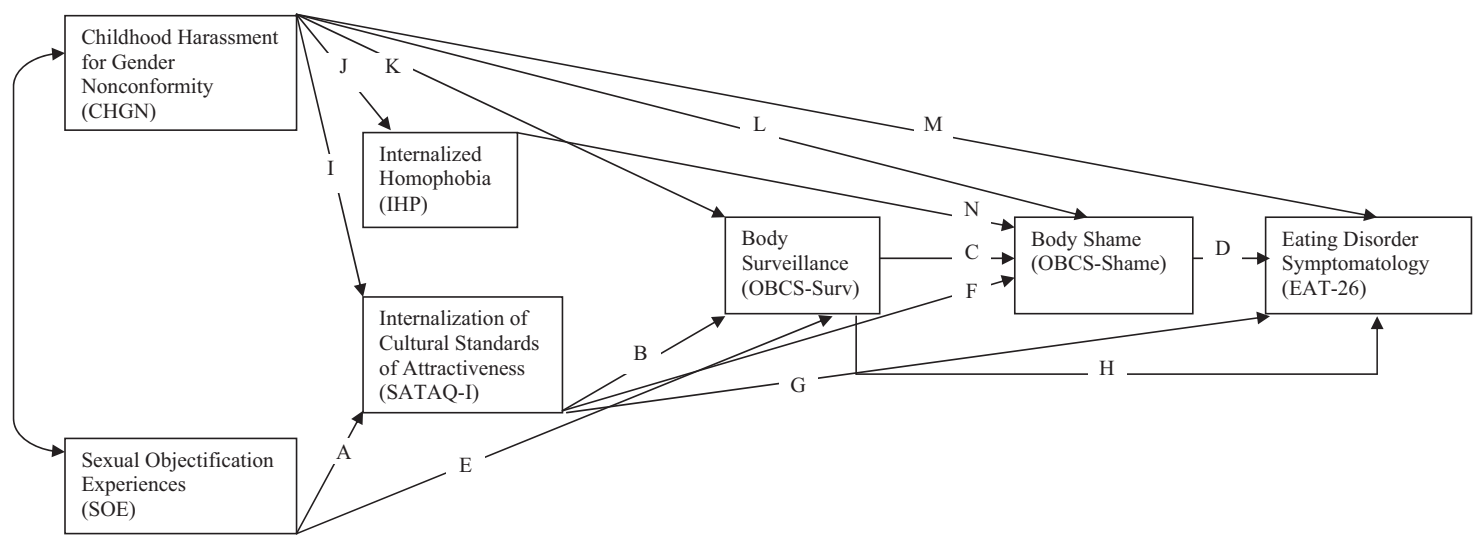

Figure 1. Conceptual model of hypothesized relations. 
path $\mathrm{A} \times \mathrm{B}$ ), and related indirectly to body shame and eating disorder symptoms through the set of relations posited in objectification theory, which include body surveillance mediating the relation of internalization with body shame (Hypothesis 3: path $\mathrm{B} \times \mathrm{C}$ ), and body shame mediating the relation of body surveillance with eating disorder symptoms (Hypothesis 4: path $\mathrm{C} \times \mathrm{D}$ ). On the basis of prior objectification theory research, additional direct relations are expected from sexual objectification experiences to body surveillance (path E), from internalization to body shame (path F) and eating disorder symptoms (path G), and from body surveillance to eating disorder symptoms (path $\mathrm{H}$ ). Thus, each of the hypothesized indirect relations reflects partial mediation.

In addition to these objectification theory-based hypotheses, the roles of internalized homophobia and childhood harassment for gender nonconformity are explored in the model. Specifically, based on Beren's (1997) findings, a positive series of relations from recalled childhood harassment for gender nonconformity to internalized homophobia (path J) to body shame (path N) to eating disorder symptoms (path D) is explored, with the expectation that body shame fully mediates the relation of internalized homophobia with eating disorder symptoms (Hypothesis 5: path $\mathrm{N} \times \mathrm{D}$ ). Also, relations of recalled harassment with internalization of cultural standards of attractiveness (path I), body surveillance (path K), body shame (path L), and eating disorder symptoms (path $\mathrm{M}$ ) are explored. Parallel to sexual objectification experiences, recalled harassment is expected to be related to body surveillance through the partial mediation of internalization of cultural standards of attractiveness (Hypothesis 6: path $\mathrm{I} \times \mathrm{B}$ ).

Finally, to provide a more stringent test of the hypotheses, body mass index (BMI) and age are explored as potential covariates. This is consistent with prior findings that BMI and age may be covariates in the links of eating disorder symptoms with their correlates (e.g., Beren, 1997; Fredrickson, Roberts, Noll, Quinn, \& Twenge, 1998; Morry \& Staska, 2001; Stice, 2002).

\section{Method}

\section{Participants}

Data from 231 individuals were analyzed. Participants selfidentified as men (97\%) or transgender (2\%), and as exclusively gay $(66 \%)$, mostly gay (20\%), bisexual $(12 \%)$, or mostly heterosexual $(2 \%)$ on a Kinsey-type scale (ranging from 1 [exclusively gay] to 5 [exclusively heterosexual]). The four men who selfidentified as mostly heterosexual and the two men who did not report their sexual orientation were retained because their responses to other items indicated some sexual orientation toward men. To capture the breadth of same- and other-sex attractions in the sexual minority continuum (Moradi, Mohr, Worthington, \& Fassinger, 2009) and supplement self-identification data, participants used a 5-point continuum (ranging from 1 [low] to 5 [high]) to rate their physical attraction to men $(M=4.77 ; M d n=5.00$; $S D=0.54)$ and to women $(M=1.66 ; M d n=1.00 ; S D=1.02)$, and their emotional attraction to men $(M=4.40 ; M d n=5.00$; $S D=0.97)$ and to women $(M=2.72 ; M d n=3.00 ; S D=1.38)$. Participants used a 5-point continuum $(1=$ men only, $3=$ both genders equally, $5=$ women only; $0=$ never had sex) to report the gender specificity of their sexual behaviors (10 participants re- ported that they never had sex; for the remaining participants, $M=$ $1.62 ; M d n=1.00 ; S D=0.79$ ).

Participants ranged in age from 17 to $70(M=32.67 ; M d n=$ 27.0; $S D=13.83$ ). About $77 \%$ identified as White or Caucasian, $5 \%$ as Hispanic or Latino, $4 \%$ as Asian American or Pacific Islander, $1 \%$ as African American, and $11 \%$ as multiracial or other races or ethnicities; $2 \%$ did not report their race/ethnicity. Participants reported residing in a variety of countries: $79 \%$ in the United States; $7 \%$ in Canada; $5 \%$ in the United Kingdom; $3 \%$ in India; and $1 \%$ or less each in Australia, Belgium, Indonesia, Iraq, the Netherlands, Portugal, South Africa, and United Arab Emirates (two of these participants indicated recent or temporary relocation from the United States). Participants' ability to read and understand the survey was indicated by the fact that they were recruited from English-language sites and responded correctly to validity check items (described below).

\section{Procedure}

The survey was made available on an Internet site hosted by the authors' institution and following guidelines for Internet research (Hewson, Laurent, \& Vogel, 1996; Michalak \& Szabo, 1998; Nosek, Banaji, \& Greenwald, 2002). Internet data collection has been recommended for recruiting difficult to reach populations (e.g., Gosling, Vazire, Srivastava, \& John, 2004; Nosek et al., 2002), including sexual minority people, some of whom may not feel comfortable "coming out" to researchers in person (Epstein \& Klinkenberg, 2002; Meyer \& Wilson, 2009; Moradi et al., 2009; Riggle, Rostosky, \& Reedy, 2005). Advertisements were sent to e-mail lists and online groups for lesbian, gay, bisexual, and transgender (LGBT) individuals (e.g., Yahoo, Google, AOL, Livejournal, MySpace LGBT groups). E-mail lists for general information exchange were included because such lists target broad sexual minority audiences (rather than subgroups with specific political, dating, or religious interests). Advertisements were also posted in local community establishments that were not LGBT specific (e.g., restaurants) and distributed through the researchers' personal contacts. In addition, e-mail lists, Internet groups, and organizations serving racial and ethnic minority LGBT individuals were targeted to increase the sample's racial and ethnic diversity.

Advertisements invited participants to the web link for a survey study about the experiences of men who identify as gay or bisexual or have sex with men. Upon connecting to the survey, the informed consent was displayed describing the confidentiality of responses and voluntary nature of participation; no compensation was offered. Participants clicked "Start the survey" to indicate that they read and understood the consent form and agreed to participate. To ensure that participants were actively (rather than randomly) choosing responses, validity check items appeared throughout the survey asking participants to mark a particular response (e.g., "please click the button for Sometimes"). Participants who marked an inaccurate response to two or more (out of 10) validity items were eliminated from analyses. The total of 274 submissions were screened to eliminate (a) 13 duplicate submissions, (b) 17 incomplete submissions, (c) 11 participants with two or more incorrect validity item responses, and (d) two participants who selfidentified as women, resulting in a final sample size of 231. Participants completed the following instruments in counterbalanced order to minimize order effects. 


\section{Instruments}

Sexual objectification experiences. Because an existing measure of sexual minority men's sexual objectification experiences could not be identified, several steps were taken to assess this construct in the present study. First, existing measures of sexual objectification experiences were reviewed, and items that were applicable to sexual minority men were identified. Next, five consultants who identified as gay or bisexual men, two of whom also had experience conducting research with sexual minority populations, were asked to evaluate the applicability of the items to sexual minority men's experiences. Finally, the consultants were asked to provide feedback about additional experiences that should be included in the assessment.

As the first step of the process, eight of 18 items from the Objectification Experiences Questionnaire (OEQ; Burnett, 1995), five of seven items from Swim, Cohen, and Hyers' (1998) measure of sexual objectification experiences, and three of 28 items from the Cultural Sexual Objectification Scale (Hill, 2002) were selected. Evidence of acceptable reliability and validity has been garnered using these measures with women (e.g., Burnett, 1995; Hill, 2002; Moradi et al., 2005; Swim et al., 1998). Items from these three measures were selected if their content seemed applicable across gender and sexual orientation groups. When there was content redundancy across measures, the most clearly stated item was selected. Minimal item modifications were made to increase applicability to sexual minority men (e.g., replacing the word breasts with body). The items were then submitted to consultants. On the basis of consultant feedback, additional wording modifications were made to increase applicability to sexual minority men (e.g., adding the word cruised to reflect terminology used by sexual minority men), and an item was added to assess the experience of being inappropriately grabbed or touched with the intent of expressing sexual interest. The final Sexual Objectification Experiences (SOE) scale used in this study was composed of 17 items. Sample items include "Felt that a date was more interested in my body (and gaining access to it) than in me as a person?" and "Someone made offensive or unwanted sexualized gestures toward me." Consistent with rating scales used in Hill's (2002) measure of sexual objectification experiences and other measures of harassment experiences (e.g., Klonoff \& Landrine, 1995; Landrine \& Klonoff, 1996), participants rated SOE items according to how often they experienced each event in the past year (ranging from 1 [never] to 6 [almost all of the time]).

A principle axis factor analysis (PAF) was conducted to evaluate the dimensionality of SOE items. Data factorability was supported by the Kaiser-Meyer-Olkin statistic (.93) and Barlett's test of sphericity, $\chi^{2}(136, N=231)=1829.58, p<.001$. Three factors had eigenvalues greater than one, but the scree plot suggested retention of one factor. The three-, two-, and one-factor solutions were explored using promax rotation to accommodate potential factor intercorrelations. The two- and three-factor solutions each yielded a factor with only three items, and many of the second and third factors' items had indistinctive factor loadings (i.e., loadings and cross-loadings were similar in magnitude). Thus, the one-factor model was retained. Item loadings ranged from .49 to .77 , and this model accounted for $43.50 \%$ of the initial variance in the data. Consistent with the unidimensionality suggested by these PFA results, corrected item-total correlations for
SOE items ranged from .48 to .72, and Cronbach's alpha was .91. Item ratings were averaged to compute an overall score, with higher scores reflecting greater reported sexual objectification experiences.

Internalization of cultural standards of attractiveness. The eight-item Internalization subscale of the Sociocultural Attitudes Towards Appearance Questionnaire (SATAQ-I; Heinberg, Thompson, \& Stormer, 1995) was used to assess internalization of cultural standards of attractiveness. Sample items include "I believe that clothes look better on muscular/fit models" and "I wish I looked like an underwear model." Each statement is rated on a 5-point continuum (ranging from 1 [completely disagree] to 5 [completely agree]). This measure originated for use with women but has been modified and used with men (e.g., Cashel, Cunningham, Landeros, Cokley, \& Muhammad, 2003; Morry \& Staska, 2001). Following prior examples, the word women was replaced with men, thin with fit/lean, swimsuit model with underwear model, and the names of women's magazines with popular men's magazines. Item ratings were averaged to compute an overall score, with higher scores reflecting greater internalization. With men of unknown sexual orientation, the validity of SATAQ-I scores was supported through positive correlations with body dissatisfaction, drive for thinness, and self-objectification (Cashel et al., 2003; Morry \& Staska, 2001). In these samples, SATAQ-I items yielded Cronbach's alphas of .79 (Cashel et al., 2003) and .78 (Morry \& Staska, 2001). The Cronbach's alpha with the present sample was .89 .

Recalled childhood harassment for gender nonconformity. Beren's (1997) childhood harassment for gender nonconformity items were used to assess the degree to which respondents recalled being criticized, rejected, and teased as a child for gender nonconformity. The measure assesses harassment from the respondent's mother, father, and peers. Sample items include "When I was a child, my mother would say I was not masculine enough" and "When I was a child, other children would call me a sissy." Items are rated on a 5-point Likert-type scale ranging from 1 (strongly disagree) to 5 (strongly agree). In this study, two items were not included in the scoring because they measured pride in masculinity rather than harassment for gender nonconformity, and they had negative corrected item-total correlations in reliability analyses. Ratings of the remaining 32 items were averaged to compute an overall score, with higher scores reflecting greater recalled childhood harassment. In terms of validity, Beren (1997) found that gay men's scores on a composite measure that included these items were correlated negatively with their perceptions of acceptance from others during the coming-out process. With her sample of gay men, Beren (1997) reported a Cronbach's alpha of .75 for items on this measure. Cronbach's alpha for the 32 retained items in the present sample was .94 .

Internalized homophobia. The nine-item Internalized Homophobia Scale (IHP; Herek, Cogan, Gillis, \& Glunt, 1998) measures respondents' internalization of societal stigma against homosexuality. Sample items are "I have tried to stop being attracted to men in general" and "If someone offered me the chance to be completely heterosexual I would accept the chance." Items are rated on a 5-point scale ranging from 1 (disagree strongly) to 5 (agree strongly). Item ratings are averaged, with higher scores reflecting greater internalized homophobia. In terms of validity, gay men's IHP scores were correlated positively with depressive 
symptoms and negatively with self-esteem (Herek et al., 1998). Cronbach's alpha for IHP items was .83 with a community sample of gay and bisexual men (Herek et al., 1998). Cronbach's alpha in the present sample was .88 .

Body surveillance. The eight-item Body Surveillance subscale of McKinley and Hyde's (1996) Objectified Body Consciousness Scale (OBCS-Surv) measures the extent to which an individual thinks of his or her body in terms of how it looks rather than how it feels. Sample items are "I think it is more important that my clothes are comfortable than whether they look good on me" (reverse coded) and "During the day, I think about how I look many times." Items are rated on a 7-point scale ranging from 1 (strongly disagree) to 7 (strongly agree), with an NA (not applicable) option for items that do not apply. Following McKinley and Hyde's (1996) scoring instructions, NA responses are coded as missing, and ratings of applicable items are averaged; higher scores indicate greater body surveillance. As evidence of validity, body surveillance scores were correlated positively with selfobjectification and body shame in a sample of gay men (Martins et al., 2007). Cronbach's alpha was .76 in a prior sample of gay men (Martins et al., 2007) and was .90 in the present sample.

Body shame. The eight-item Body Shame subscale of McKinley and Hyde's (1996) Objectified Body Consciousness Scale (OBCS-Shame) measures level of body shame. Sample items are "I feel like I must be a bad person when I don't look as good as I could" and "When I'm not the size I think I should be, I feel ashamed." Items are rated on a 7-point scale ranging from 1 (strongly disagree) to 7 (strongly agree), with an NA (not applicable) option for items that do not apply. Following McKinley and Hyde's (1996) scoring instructions, NA responses are coded as missing, and ratings of applicable items are averaged; higher scores indicate greater body shame. As evidence of validity, body shame scores were correlated positively with drive for thinness and body surveillance in a sample of gay men (Martins et al., 2007). Cronbach's alpha was .81 in a prior sample of gay men (Martins et al., 2007) and was .89 in the present sample.

Eating disorder symptoms. The Eating Attitudes Test-26 (EAT-26; Garner, Olmsted, Bohr, \& Garfinkel, 1982) is a 26-item measure of eating disorder symptoms recommended for use with nonclinical samples (Siever, 1994). Sample items include "Avoid eating when I am hungry" and "Have the impulse to vomit after meals." Items are rated on a 6-point continuum (ranging from 1 [never] to 6 [always]); averaging continuous ratings to obtain an overall score is recommended in nonclincial samples (Siever, 1994). EAT-26 scores differentiate between individuals with a diagnosable eating disorder and nonclinical controls and are correlated as expected with scores on other measures of disordered eating (Kashubeck-West, Mintz, \& Saunders, 2001). Cronbach's alpha for EAT-26 items was .83 (Reilly \& Rudd, 2006) and .89 (Russell \& Keel, 2002) in prior samples of gay men, and was .90 in the present sample.

BMI. BMI was computed from participants' reported height and weight using the Centers for Disease Control and Prevention formula: [Weight in pounds/(height in inches) ${ }^{2}$ ] $\times$ 703). Selfreports of height and weight are highly correlated with measured values and are recommended as a practical method to assess BMI (Goodman \& Strauss, 2003).

\section{Results}

\section{Descriptive Information and Preliminary Analyses}

Participants' EAT-26 scores $(M=2.35, S D=0.70)$ indicated that, on average, they reported experiencing eating problems between "rarely" and "sometimes." According to the National Center for Health Statistics (2007) criteria, the sample's average BMI $(M=27.03, S D=7.47)$ was in the overweight category, with $4 \%$ of participants categorized as underweight (BMI $<18.5)$, $39 \%$ as healthy weight (BMI of 18.5-24.9), 32\% as overweight (BMI of $25-30$ ), and $24 \%$ as obese (BMI $\geq 30$ ). National BMI statistics suggest that $71 \%$ of adult men (sexual orientation unspecified) are overweight or obese, and $28 \%$ are healthy weight (National Center for Health Statistics, 2007); comparatively, a larger percentage of the present sample was in the healthy weight category, and a smaller percentage was in the overweight/obese category.

A series of multivariate analyses of variance (MANOVAs), with the set of variables of interest (i.e., sexual objectification experiences, internalization of cultural standards of attractiveness, body surveillance, body shame, harassment for childhood gender nonconformity, internalized homophobia, and eating disorder symptoms) as the dependent variables, indicated no significant overall group difference on order of instruments, $F(7,223)=1.42, p>$ .05 ; racial/ethnic minority or nonminority status, $F(7,219)=0.78$, $p>.05$; and U.S. or non-U.S. residence, $F(7,219)=2.03, p>$ .05 . There was an overall effect for sexual orientation identification, $F(21,663)=3.85, p<.001$. Follow-up univariate tests, with alpha adjusted $(.05 / 7=.007)$ to control for Type I error, yielded a significant effect for internalized homophobia, $F(3,225)=$ $12.57, p<.001$. Post hoc tests indicated that men who identified as exclusively gay had a lower internalized homophobia average $(M=1.47, S D=0.63)$ compared with men who identified as mostly gay $(M=2.10, S D=0.98)$ or bisexual $(M=2.13, S D=$ 0.90); the latter two groups did not differ from each other or from men who identified as mostly heterosexual. There were no significant sexual orientation identification differences on the other six variables of interest. To examine whether interrelations of the variables included in the path model differed across sexual orientation groups (which would suggest model invariance), we conducted a Box's test of equality of covariance matrices, with the variables of interest as dependent variables and sexual orientation identification as the independent variable. Results indicated that covariances were invariant (Box's $M=66.80, p=.29$ ), suggesting that the variables in the path model yielded similar interrelations across the four sexual orientation identity groups. Box's test and the MANOVA results remained the same when men who identified as mostly heterosexual were excluded from analysis.

BMI was correlated with internalization of cultural standards of attractiveness $(r=-.13, p<.05)$, body surveillance $(r=-.13$, $p<.05)$, and body shame $(r=.13, p<.05)$. Age was correlated with experiences of sexual objectification $(r=-.32, p<.001)$, internalization of cultural standards of attractiveness $(r=-.22$, $p<.01)$, internalized homophobia $(r=-.24, p<.001)$, body surveillance $(r=-.35, p<.001)$, and body shame $(r=-.22$, $p<.01)$. These statistically significant links involving BMI and age were included in subsequent analyses. 


\section{Relations Among Objectification Theory Variables}

Partial correlations, controlling for BMI and age, were consistent with Hypothesis 1, indicating positive relations among sexual objectification experiences, internalization of cultural standards of attractiveness, body surveillance, body shame, and eating disorder symptoms (see Table 1). These variables also were correlated positively with internalized homophobia and recalled childhood harassment for gender nonconformity. But, internalized homophobia was not correlated significantly with childhood harassment for gender nonconformity.

\section{Path Analysis of Direct and Indirect Relations Based on the Objectification Theory Framework}

To test the relations posited in Hypotheses 2-6, we used Amos 7.0 (Arbuckle, 2006) to conduct a path analysis of the model depicted in Figure 1. We tested the model with manifest variables because internal consistency reliabilities for all indicators were in the excellent range (according to Ponterotto \& Ruckdeschel's, 2007, matrix for estimating the adequacy of Cronbach's alpha), thus, reducing potential gains of using item parceling and latent variable modeling to estimate unique variance and measurement error. Indeed, scores on this study's measures are typically modeled as manifest indicators in prior research. Direct paths were not estimated if prior conceptual or empirical literature did not support their inclusion in the model (i.e., sexual objectification experiences to internalized homophobia, body shame, and eating disorder symptoms; internalized homophobia to body surveillance and eating disorder symptoms; Beren, 1997; Kozee \& Tylka, 2007; Moradi et al., 2005; Reilly \& Rudd, 2006). In addition, we included BMI and age in the model by estimating their links with the variables with which they were significantly correlated. We did not have conceptual or empirical basis for a directional hypothesis about the relation between internalized homophobia and internalization of cultural standards of attractiveness. But, these two constructs are conceptually related in that they reflect internalization of dominant cultural values; thus, we modeled their disturbances to be correlated to account for a nondirectional relation between the two variables.

Data for all indicators met the guidelines for univariate normality summarized by Weston and Gore (2006) (i.e., skewness index $\leq 3.0$, kurtosis index $\leq 10.0$ ). With regard to multivariate normality, none of the cases had Mahalanobis distances that iden- tified them as multivariate outliers (i.e., $p<.001$; Tabachnick \& Fidell, 2001). We examined multiple fit indices to evaluate model fit. For sample sizes of fewer than 500, comparative fit index (CFI) values greater than .90 and root-mean-square error of approximation (RMSEA) and standardized root-mean-square residual (SRMR) values less than 10 suggest an acceptable fit (Weston \& Gore, 2006). Fit index values for the present model met these guidelines and were as follows: $\mathrm{CFI}=.98, \mathrm{RMSEA}=.08(90 \%$ CI: .03-.12), and SRMR $=.03$. The model accounted for $7 \%$ of the variance in internalized homophobia, $11 \%$ of the variance in internalization of cultural standards of attractiveness, $46 \%$ of the variance in body surveillance, $53 \%$ of the variance in body shame, and $38 \%$ of the variance in eating disorder symptoms. As indicated in Figure 2, most of the standardized path coefficients for direct links between the variables of interest were significant; exceptions were the nonsignificant direct paths from recalled childhood harassment for gender nonconformity to internalized homophobia (path $\mathrm{J}$ ) and eating disorder symptoms (path $\mathrm{M}$ ) and from internalization of cultural standards of attractiveness to eating disorder symptoms (path G).

To test the significance of the hypothesized indirect relations, we used a bootstrap procedure with 1,000 bootstrap samples from the original data to compute bias-corrected $95 \%$ confidence intervals (CI) for indirect effects; if the $95 \%$ CI does not include 0 , then the indirect link is statistically significant at $p<.05$ (Mallinckrodt, Abraham, Wei, \& Russell, 2006; Shrout \& Bolger, 2002). Consistent with Hypothesis 2, reported sexual objectification experiences had a significant positive indirect relation with body surveillance through internalization of cultural standards of attractiveness (path $\mathrm{A} \times \mathrm{B} ; b=.14$ [95\% CI: .013-.300], $\beta=.14 \times .51=.07)$. Consistent with Hypothesis 3, internalization of cultural standards of attractiveness had a significant positive indirect relation with body shame through body surveillance (path $\mathrm{B} \times \mathrm{C} ; b=.26[95 \%$ CI: .163-.381], $\beta=.51 \times .32=.16$ ). Consistent with Hypothesis 4 , body surveillance had a significant positive indirect relation with eating disorder symptoms through body shame (path $\mathrm{C} \times \mathrm{D}$; $b=.06$ [95\% CI: .028-.099], $\beta=.32 \times .38=.12)$. Significant total indirect relations (through multiple indirect pathways) also emerged from sexual objectification experiences to body shame $(b=.23$ [95\% CI: .076-.391], $\beta=.11)$ and eating disorder symptoms $(b=.09$ [95\% CI: .031-.153], $\beta=.10)$, and from internalization of cultural standards of attractiveness to eating disorder symptoms ( $b=.23$ [95\% CI: .161-.309], $\beta=.33$ ). These

Table 1

Summary Statistics and Partial Correlations Among Variables of Interest With Body Mass Index and Age Controlled

\begin{tabular}{|c|c|c|c|c|c|c|c|c|c|c|c|c|}
\hline Variable & 1 & 2 & 3 & 4 & 5 & 6 & 7 & $\begin{array}{c}\text { Possible } \\
\text { range }\end{array}$ & $\begin{array}{c}\text { Sample } \\
\text { range }\end{array}$ & $M$ & $S D$ & $\propto$ \\
\hline 1. Sexual objectification experiences & - & & & & & & & $1-6$ & $1.12-4.65$ & 2.28 & 0.74 & .91 \\
\hline 2. Childhood harassment for gender nonconformity & $.22^{* *}$ & - & & & & & & $1-5$ & $1.19-4.81$ & 2.62 & 0.75 & .94 \\
\hline 3. Internalization of cultural standards of attractiveness & $.21^{* *}$ & $.18^{* *}$ & - & & & & & $1-5$ & $1.00-5.00$ & 3.31 & 0.99 & .89 \\
\hline 4. Internalized homophobia & $.14^{*}$ & .10 & $.32^{* *}$ & - & & & & $1-5$ & $1.00-5.00$ & 1.69 & 0.81 & .88 \\
\hline 5. Body surveillance & $.26^{* *}$ & $.28^{* *}$ & $.58^{* * *}$ & $.18^{* * *}$ & - & & & $1-7$ & $1.00-7.00$ & 4.37 & 1.46 & .90 \\
\hline 6. Body shame & $.23^{* *}$ & $.30^{* *}$ & $.61^{* *}$ & $.36^{* *}$ & $.58^{* * *}$ & - & & $1-7$ & $1.00-7.00$ & 3.48 & 1.56 & .89 \\
\hline 7. Eating disorder symptoms & $.25^{* *}$ & $.25^{* *}$ & $.44^{* *}$ & $.20^{*}$ & $.54^{* * *}$ & $.59^{* *}$ & - & $1-6$ & $1.08-4.62$ & 2.35 & 0.70 & .90 \\
\hline
\end{tabular}

Note. $\quad N=231$. Higher scores indicate higher levels of the construct assessed

${ }^{*} p<.05$. *** $p<.01$. 


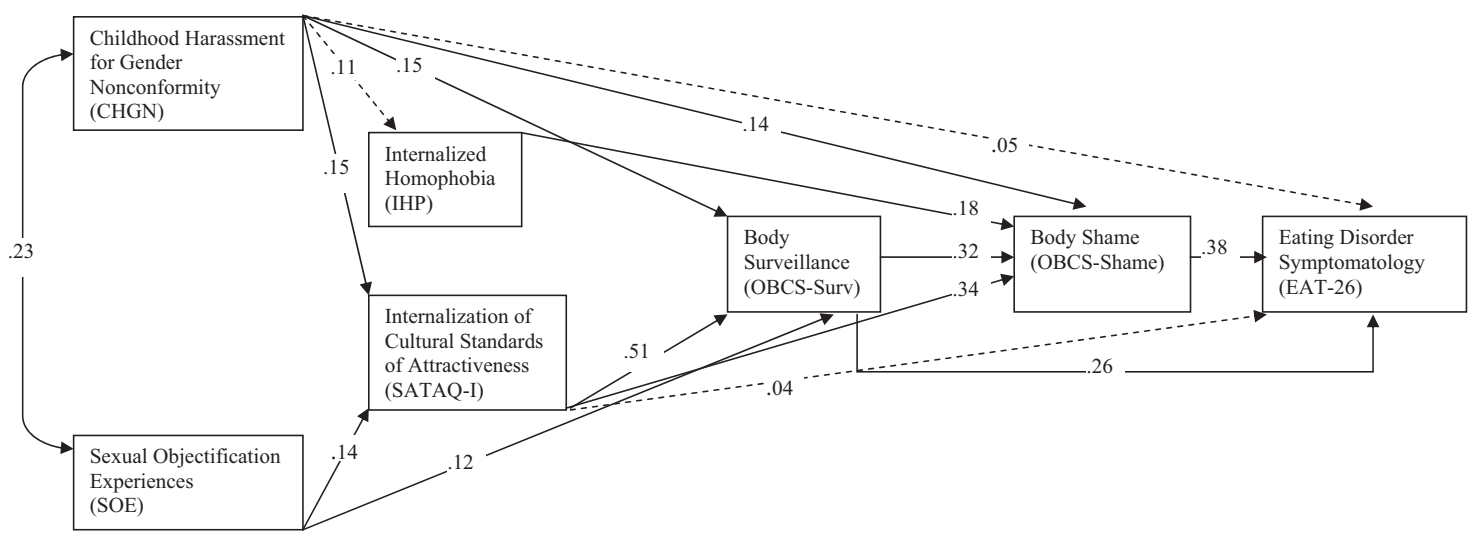

Figure 2. Path model of direct and indirect relations among variables of interest. Values reflect standardized coefficients. Dashed lines indicate nonsignificant paths; all other depicted paths are significant at ${ }^{*} p<.05$. The following parameters were also estimated but omitted from the figure for the sake of parsimony: paths from body mass index (BMI) to SATAQ-I $=-.13^{*}$, OBCS-Surv $=-.02$, and OBCS-Shame $=.20^{*}$; paths from age to SATAQ-I $=-.13$, IHP $=-.22^{*}$, OBCS-Surv $=-.18^{*}$, and OBCS-Shame $=-.03$; correlations of BMI with $\mathrm{CHGN}=.09$ and with $\mathrm{SOE}=-.13$; correlations of age with $\mathrm{CHGN}=-.11, \mathrm{SOE}=-.32^{*}$, and $\mathrm{BMI}=.24^{*}$; correlation between the residuals of IHP and SATAQ-I $=.30^{*}$.

indirect relations reflected partial mediation, as the direct relations from reported sexual objectification experiences to body surveillance (path E), from internalization of cultural standards of attractiveness to body shame (path F) and eating disorder symptoms (path $\mathrm{G}$ ), and from body surveillance to eating disorder symptoms (path $\mathrm{H}$ ) were nonzero and statistically significant.

\section{Exploration of Roles of Internalized Homophobia and Recalled Childhood Harassment for Gender Nonconformity}

Consistent with Beren's (1997) findings and Hypothesis 5, internalized homophobia had a significant positive indirect relation with eating disorder symptoms through body shame (path $\mathrm{N} \times \mathrm{D}$; $b=.06$ [95\% CI: .019-.113], $\beta=.18 \times .38=.07)$; this reflected full mediation, as no additional path was estimated from internalized homophobia to eating disorder symptoms. Furthermore, parallel to the role of reported sexual objectification experiences and consistent with Hypothesis 6, recalled childhood harassment for gender nonconformity had a significant positive indirect relation with body surveillance through internalization of cultural standards of attractiveness (path I $\times \mathrm{B} ; b=.15$ [95\% CI: .003-.298], $\beta=.15 \times .51=.08)$. Significant total indirect relations also emerged from recalled childhood harassment to body shame $(b=$ .30 [95\% CI: .109-.469], $\beta=.14$ ) and eating disorder symptoms ( $b=.16$ [95\% CI: .078-.250], $\beta=.17$ ). All indirect relations of recalled childhood harassment reflected partial mediation as they included multiple indirect pathways involving direct links with internalization of cultural standards of attractiveness (path I), body surveillance (path K), and body shame (path L). Inconsistent with Beren's (1997) findings, however, recalled childhood harassment was not related directly and uniquely with internalized homophobia (path J).

\section{Nested Model Comparisons}

Examination of modification indices for the unestimated paths from sexual objectification experiences to internalized homopho- bia, body shame, and eating disorder symptoms, and from internalized homophobia to body surveillance and eating disorder symptoms indicated that their estimation would not have resulted in substantial improvement in model fit (i.e., none of the modification index values were statistically significant at $p<.05$ ). Thus, comparisons of more complex models (with additional estimated paths) were not deemed to be necessary. To evaluate a more parsimonious model, we conducted a nested model comparison comparing the model depicted in Figure 1 with a model that constrained to zero (i.e., eliminated) predictor-criterion direct paths where a significant indirect effect was found (paths E, F, G, $\mathrm{H}, \mathrm{K}, \mathrm{L}, \mathrm{M})$. Fit index values for the constrained model suggested inadequate fit (CFI $=.85$, RMSEA $=.15$ [90\% CI: .12 to .18], SRMR $=.09)$ and the chi-square change for the nested model comparison suggested significantly poorer fit relative to the original model, $\Delta \chi^{2}(7, N=231)=73.56, p<.001$.

To explore the importance of recalled childhood harassment for gender nonconformity and internalized homophobia within the objectification theory framework, we conducted a series of nested model comparisons, comparing the model depicted in Figure 1 with models that constrained to zero the paths to other variables from (a) childhood harassment for gender nonconformity and internalized homophobia (paths I through N), (b) childhood harassment for gender nonconformity (paths I, J, K, L, M), and (c) internalized homophobia (path N). The first nested model evaluated the combined roles of childhood harassment and internalized homophobia, and the subsequent two nested models allowed for specifying whether potential reduction in fit for the first model (model a) was due to the role of childhood harassment (model b), or internalized homophobia (model c), or both. Fit index values for the model that constrained the links of childhood harassment for gender nonconformity and internalized homophobia were CFI = .92, RMSEA $=.11(90 \%$ CI: $.08-.15)$, SRMR $=.08$. Fit index values for the model that constrained the links of childhood harassment for gender nonconformity were CFI $=.94$, RMSEA $=$ $.10(90 \%$ CI: .07-.14), SRMR $=.08$. Fit index values for the model that constrained the links of internalized homophobia were 
$\mathrm{CFI}=.96, \mathrm{RMSEA}=.11(90 \% \mathrm{CI}: .07-.15), \mathrm{SRMR}=.04$. The chi-square change for each of the nested model comparisons was significant, suggesting that the model that eliminated the role of (a) childhood harassment for gender nonconformity and internalized homophobia, $\Delta \chi^{2}(6, N=231)=36.57, p<.001$; (b) harassment for gender nonconformity, $\Delta \chi^{2}(5, N=231)=23.92, p<.001$; and (c) internalized homophobia, $\Delta \chi^{2}(1, N=231)=12.22, p<$ .001 , each provided a poorer fit to the data than did the original model.

\section{Discussion}

The present study supports a number of tenets of objectification theory with sexual minority men and also elucidates roles of internalized homophobia and recalled harassment for gender nonconformity within this framework. As such, the findings of this study can inform future research and practice with sexual minority men.

First, this study extends prior support for objectification theory with heterosexual and lesbian women (e.g., Kozee \& Tylka, 2007; Kozee et al., 2007; Moradi et al., 2005; Noll \& Fredrickson, 1998) to sexual minority men. Specifically, results were consistent with relations posited in objectification theory from sexual objectification experiences to internalization of cultural standards of attractiveness, body surveillance, body shame, and eating disorder symptoms. Within this set of positive relations, internalization of cultural standards of attractiveness mediated the link of sexual objectification experiences with body surveillance; body surveillance mediated the link of internalization with body shame; and body shame mediated the link of body surveillance with eating disorder symptoms. In terms of practice, these findings point to challenging and reducing cultural and interpersonal sexual objectification of sexual minority men as important avenues for prevention. Such efforts may include public education campaigns (through media outlets, health service providers, and cultural events) to broaden depictions of attractiveness and challenge sexualization of sexual minority men.

Additional important findings were the links of recalled childhood harassment for gender nonconformity with body surveillance, body shame, and eating disorder symptoms. The relations involving recalled harassment for gender nonconformity paralleled relations involving reported sexual objectification experiences. That is, harassment for gender nonconformity was linked with eating disorder symptoms through a positive set of relations involving internalization of cultural standards of attractiveness, body surveillance, and body shame. This pattern is consistent with the possibility that childhood harassment for gender nonconformity is a form of objectification that promotes efforts to monitor and control one's bodily appearance (i.e., body surveillance). In practice, these findings suggest attending to clients' experiences of sexual objectification and childhood harassment for gender nonconformity and assessing the extent to which such experiences are linked with clients' body monitoring. It also seems important to avoid blaming clients for appearance preoccupation by considering that, within a context of harassment for gender nonconformity, body monitoring may have the self-protective function of preventing further harassment and potential violence. Thus, considering functional and potentially harmful aspects of body monitoring within the context of clients' lives seems warranted.
It is important to note that this study focused on recalled childhood harassment for gender nonconformity but did not assess current experiences of harassment. Teasing apart the roles of childhood and current experiences of harassment for gender nonconformity is complicated by reliance on retrospective accounts of childhood harassment. Retrospective accounts may be necessary given the inherent challenges of identifying and gathering data about sexual minority boys in childhood, but recall may be conflated with the salience of current harassment for gender nonconformity. Despite these complexities, researchers can evaluate the overlap between recalled childhood and current experiences of harassment for gender nonconformity and explore the relative links of these reports with objectification theory constructs.

The present results also suggest that internalization of cultural standards of attractiveness, body surveillance, and body shame may link perceived experiences of sexual objectification and recalled childhood harassment for gender nonconformity with eating disorder symptoms. Thus, efforts that target these intervening variables may be important in prevention and therapy. For example, critically examining the consequences of sexual objectification may be useful. On an individual level, a client may have an immediate positive response to being treated as sexually appealing, but he may engage in persistent body surveillance if his sexual appeal dominates his self-worth, or may feel body shame if he is not treated as sexually appealing on future occasions. On a collective level, when sexual appeal dominates societal views of a particular group, group members may feel pressure to meet such expectations. Failing to meet such expectations may have deleterious consequences for individual well-being (e.g., feelings of shame) and collective identity (e.g., lack of belonging to the group). Critical examination of immediate and long-term as well as individual and collective implications of events may help to interrupt clients' internalization of sexual objectification and harassment for gender nonconformity experiences.

Finally, building on Beren's (1997) findings that internalized homophobia was linked with eating disorder symptoms through feelings of shame, the present results suggest that body-specific shame mediates the link of internalized homophobia with eating disorder symptoms among sexual minority men. It may be obvious to consider the implications of internalized homophobia for identity development and coming out processes; the present findings suggest that attending to body image implications of internalized homophobia may be important in therapy as well. The present findings differed from Beren's (1997) results in pointing to internalization of cultural standards of attractiveness, rather than internalized homophobia, as a mediator in the link of recalled childhood harassment for gender nonconformity with body image and eating problems. This divergence illustrates the utility of considering specific versus general levels of assessment (Moradi et al., 2009). Beren (1997) assessed a composite of gender nonconformity and other general experiences of childhood harassment and found this general negative experiences variable to be linked with internalized homophobia. In the present study, informed by objectification theory, we isolated gender nonconformity-specific harassment and internalization of cultural standards of attractiveness, both of which may be more specifically relevant to body image issues than global negative treatment and internalized homophobia. 
In considering the aforementioned practice implications of the findings, it is important to note that except for the fully mediated relation of internalized homophobia with eating disorder symptoms by body shame, all other indirect relations reflected partial mediation. As such, these findings suggest the promise of interventions that target both predictor and mediator variables. The magnitudes of relations in the model point to internalization of cultural standards of attractiveness, body surveillance, and body shame as the most fruitful targets of intervention. For example, it may be useful to help clients explore cultural standards of attractiveness: Where do they receive these messages most strongly (e.g., magazines, gym, sports)? Can they reduce or resist their exposure to such messages? Educating clients about image modification in advertising might help to challenge the legitimacy of cultural standards of attractiveness and their power to induce body surveillance and body shame. Similarly, deconstructing clients' body surveillance efforts might encourage their sense of agency in this regard: Some body surveillance efforts may be rooted in cultural attractiveness standards and promote body shame for failing to meet those standards; other body surveillance strategies may reflect warranted vigilance about harassment for gendernonconforming appearance. This distinction may open clients to reduce harmful body surveillance and resultant body shame. Collectively, these example strategies aim to interrupt clients' adoption of cultural standards of attractiveness and the potential translation of such internalization into body surveillance, body shame, and eating disorder symptoms.

\section{Limitations and Directions for Future Research}

A number of limitations should be considered in interpreting the present findings. First, self-reports of sexual objectification experiences and childhood harassment for gender non-conformity are important to assess and have been a focus of prior research. Because self-reports can be influenced by memory recall and subjective interpretations of events, there is continued utility in experimental studies that evaluate outcomes of sexually objectifying situations (for a review, see Moradi \& Huang, 2008). Still, it is important to acknowledge the inherent subjectivity in how events are experienced. For example, some individuals may perceive sexual attention as affirming. Indeed, some participants in the present study commented (in an open-response comment box) that they dressed or behaved in ways to invite sexual attention from other men. This raises questions about the role of subjective valence of events. Are positively interpreted sexually objectifying events linked with body image and eating problems or does the valence of events moderate this link? Research with women suggests that positively perceived appearance-related compliments are related to greater body surveillance and body dissatisfaction (Calogero, Herbozo, \& Thompson, 2009). It seems fruitful to study the subjective interpretations of events rather than treat such subjectivity as error to be controlled or eliminated.

Another limitation of this study is its cross-sectional design. Given limited available research on sociocultural correlates of eating disorder symptoms among sexual minority men, crosssectional data can provide useful groundwork for further research. However, experimental and longitudinal research is needed to test causal and temporal relations suggested by the present findings. Testing the effectiveness of interventions that target objectification theory variables can elucidate causal chains proposed in the model and inform clinical interventions as well.

In addition, this study's recruitment strategies and sample characteristics limit the generalizability of its findings. Despite its many advantages, Internet recruitment limits participation to those who have access to a computer and the Internet (e.g., Meyer \& Wilson, 2009). Also, social networking sites (e.g., MySpace) and virtual worlds (e.g., Second Life) offer opportunities for anonymous social interactions that may promote honesty in online surveys but also make them susceptible to identity experimentation. For instance, some image conscious participants might offer forthright reports of their age, body size, and attitudes under anonymous conditions, whereas others may be tempted to answer according to their ideal identity. These limitations can also apply to phone, mail, and in-person surveys where independent verification of self-reports is atypical (e.g., age) or impossible (e.g., sexual orientation). Also, despite some advertisements in non-LGBTspecific venues, most of our recruitment occurred through sexual minority groups, and we may not have reached many individuals outside of such groups. As well, the size of these groups cannot be determined or inform estimates of participation rate because online groups are in flux, and many do not maintain or share membership information. Such sampling limitations are common in studies with sexual minority people and underscore the need to assess sexual orientation in national probability studies to offer data about typically missed segments of sexual minority populations (Meyer \& Wilson, 2009; Moradi et al., 2009).

Continued attention to within-group variability in sexual minority populations is also important. The present sample was diverse in terms of age and geographic location; but, the majority of participants reported having at least a college degree and identified as White or Caucasian, middle class, and gay. Across sexual orientation identity categories, the mean levels and interrelations of the variables of interest were generally similar. One exception was that exclusively gay participants had a lower average level of internalized homophobia than did other participants. Thus, future research might explore the role of internalized homophobia across sexual minority groups. Also, the sample included a small proportion of non-U.S. residents who may have been native, long-term, or temporary residents of other countries (two participants commented that their relocation from the United States to another country was recent or temporary). These individuals were recruited from English-language sites and could read and understand English (as evident by their responses to validity check items); they also did not differ from U.S. residents on the variables of interest. Thus, the present findings cannot be assumed to generalize to non-U.S. populations. Future research is needed to assess generalizability of the findings beyond the present sample characteristics and to heterosexual men as well.

Instrumentation limitations are also important to consider. The paucity of theory and research about men's body image problems is a challenge in operationalizing key body image constructs. Indeed, most of the objectification theory measures used in the present study were developed originally with women. Although these measures have yielded acceptable psychometric properties and meaningful results with men, there are avenues for psychometric advancement. For example, cultural idealization of men's muscularity may shape men's experiences (e.g., Thompson \& Cafri, 2007). Given the root of objectification theory in women's 
experiences, however, muscularity is not explicitly reflected in measures of its key constructs. As an example, four of the eight OBCS-Shame items assess shame about body weight or size (e.g., "I would be ashamed for people to know what I really weigh"). Although they do not specify lower weight, these items may be interpreted to reflect shame for not being thin enough rather than shame about not being muscular enough. Related to this possibility is that Cronbach's alpha for OBCS-Shame items with the present sample (.89) and in Martins et al.'s (2007) sample of gay men (.81) are higher than in samples of heterosexual men (e.g., .70 in Martins et al. 2007). The present study's higher Cronbach's alphas may be because use of validity check items promoted attentive responding and eliminated random responders. Another possibility is that weight items are linked more closely with other body shame items for sexual minority men because thinness-focused body image problems are more salient for sexual minority men than for heterosexual men (e.g., Martins et al., 2007; Siever, 1994). Thus, exploring men's experiences of objectification theory constructs, integrating thinness and muscularity concerns in instrumentation, and examining muscularity-related criterion variables (e.g., drive for muscularity, steroid use) seem warranted.

Another important direction for research is to integrate additional risk and protective factors beyond internalized homophobia and recalled childhood harassment for gender nonconformity. For example, in samples of sexual minority men, childhood sexual abuse was associated with eating disorders, connection with appearance-focused gay communities garnered mixed support as a risk factor, and connection with gay-affirming communities was not supported as a protective factor (Feldman \& Meyer, 2007a, 2007b). Diversity in attractiveness standards may be important in examining the role of community connection in body image and eating problems. For example, Bear communities may value large body frames, body hair, and other masculine appearance markers (Hennen, 2005). Considering subcultures also suggests exploration of whether different subcultures' body ideals (e.g., thin vs. muscular) have different implications for body image and eating problems.

There is much to be learned about sexual minority men's body image. Within the context of limited theoretically grounded research about sexual minority men's body image problems, the present study is an attempt to integrate findings of prior research with objectification theory. Future efforts are needed to advance theoretically grounded understanding of sexual minority men's body image and eating problems. Research with sexual minority men also can inform the larger literature on the role of culture in body image and eating problems.

\section{References}

Andersen, A. E. (1999). Eating disorders in gay males. Psychiatric Annals, 29, 206-212.

Arbuckle, J. L. (2006). Amos (Version 7.0) [Computer program]. Chicago, IL: SPSS.

Aubrey, J. S. (2006). Effects of sexually objectifying media on selfobjectification and body surveillance in undergraduates: Results of a 2-year panel study. Journal of Communication, 56, 366-386. doi: 10.1111/j.1460-2466.2006.00024.x

Beren, S. E. (1997). Stigmatization and shame as determinants of subclinical eating disorder pathology: A comparison of gay and heterosexual men. Unpublished doctoral dissertation, Harvard University.
Beren, S. E., Hayden, H. A., Wilfley, D. E., \& Grilo, C. M. (1996). The influence of sexual orientation on body dissatisfaction in adult men and women. International Journal of Eating Disorders, 20, 135-141. doi:10.1002/(SICI)1098-108X(199609)20:2<135::AID-EAT3>3.0.CO 2- $\mathrm{H}$

Brand, P. A., Rothblum, E., \& Solomon, L. J. (1992). A comparison of lesbians, gay men, and heterosexuals on weight and restrained eating. International Journal of Eating Disorders, 11, 253-259. doi:10.1002/ 1098-108X(199204)11:3<253::AIDEAT2260110308>3.0.CO;2-J

Burnett, R. E. (1995). Gendered objectification experiences: Construct validity, implications for dysphoria and depression, and phenomenology. Unpublished doctoral dissertation, Duke University.

Calogero, R. M., Herbozo, S., \& Thompson, J. K. (2009). Complimentary weightism: The potential costs of appearance-related commentary for women's self-objectification. Psychology of Women Quarterly, 33, 120 132. doi:10.1111/j.1471-6402.2008.01479.x

Cashel, M. L., Cunningham, D., Landeros, C., Cokley, K. O., \& Muhammad, G. (2003). Sociocultural attitudes and symptoms of bulimia: Evaluating the SATAQ with diverse college groups. Journal of Counseling Psychology, 50, 287-296. doi:10.1037/0022-0167.50.3.287

Clark, D. (1995). Commodity lesbianism. In G. Dines \& J. Humez (Eds.), Gender, race and class in media: A text reader (pp. 142-151). Thousand Oaks, CA: Sage.

Crosscope-Happel, C., Hutchins, D. E., Getz, G. H., \& Hayes, G. L. (2000). Male anorexia nervosa: A new focus. Journal of Mental Health Counseling, 22, 365-370.

Epstein, J., \& Klinkenberg, W. D. (2002). Collecting data via the internet: The development and deployment of a web-based survey. Journal of Technology in Human Services, 19, 33-47. doi:10.1300/J017v19n02_04

Feldman, M. B., \& Meyer, I. H. (2007a). Childhood abuse and eating disorders in gay and bisexual men. International Journal of Eating Disorders, 40, 418-423. doi:10.1002/eat.20378

Feldman, M. B., \& Meyer, I. H. (2007b). Eating disorders in diverse lesbian and gay populations. International Journal of Eating Disorders, 40, 218-226. doi:10.1002/eat.20360

Fredrickson, B. L., \& Roberts, T. A. (1997). Objectification theory: Toward understanding women's lived experiences and mental health risks. Psychology of Women Quarterly, 21, 173-206. doi:10.1111/j.14716402.1997.tb00108.x

Fredrickson, B. L., Roberts, T. A., Noll, S. M., Quinn, D. M., \& Twenge, J. M. (1998). That swimsuit becomes you: Sex differences in selfobjectification, restrained eating, and math performance. Journal of Personality and Social Psychology, 75, 269-284. doi:10.1037/00223514.75.1.269

French, S. A., Story, M., Remafedi, G., Resnick, M. D., \& Blum, R. W. (1996). Sexual orientation and prevalence of body dissatisfaction and eating disordered behaviors: A population-based study of adolescents. International Journal of Eating Disorders, 19, 119-126. doi:10.1002/(SICI)1098108X(199603)19:2<119::AID-EAT2>3.0.CO;2-Q

Garner, D. M., Olmsted, M. P., Bohr, Y., \& Garfinkel, P. E. (1982). The Eating Attitudes Test: Psychometric features and clinical correlates. Psychological Medicine, 12, 871-878. doi:10.1017/S0033291700049163

Goodman, E., \& Strauss, R. (2003). Self-reported height and weight and the definition of obesity in epidemiological studies. Journal of Adolescent Health, 33, 104-141. doi:10.1016/S1054-139X(03)00247-7

Gosling, S. D., Vazire, S., Srivastava, S., \& John, O. P. (2004). Should we trust web-based studies? A comparative analysis of six preconceptions about internet questionnaires. American Psychologist, 59, 93-104. doi: 10.1037/0003-066X.59.2.93

Grabe, S., Hyde, J. S., \& Lindberg, S. M. (2007). Body objectification and depression in adolescents: The role of gender, shame, and rumination. Psychology of Women Quarterly, 31, 164-175. doi:10.1111/j.14716402.2007.00350.x

Hallsworth, L., Wade, T., \& Tiggemann, M. (2005). Individual differences 
in male body-image: An examination of self-objectification in recreational body builders. British Journal of Health Psychology, 10, 435465. doi:10.1348/135910705X26966

Heffernan, K. (1994). Sexual orientation as a factor in risk for binge-eating and bulimia nervosa: A review. International Journal of Eating Disorders, 16, 335-347. doi:10.1002/1098-108X(199412)16:4<335:: AID-EAT2260160403>3.0.CO;2-C

Heinberg, L. J., Thompson, J. K., \& Stormer, S. (1995). Development and validation of the Sociocultural Attitudes Toward Appearance Questionnaire. International Journal of Eating Disorders, 17, 81-89. doi:10.1002/ 1098-108X(199501)17:1<81::AID-EAT2260170111>3.0.CO;2-Y

Hennen, P. (2005). Bear bodies, bear masculinity: Recuperation, resistance, or retreat? Gender \& Society, 19, 25-43. doi:10.1177/ 0891243204269408

Herek, G. M., Cogan, J. C., Gillis, J. R., \& Glunt, E. K. (1998). Correlates of internalized homophobia in a community sample of lesbians and gay men. Journal of the Gay and Lesbian Medical Association, 2, 17-25.

Hewson, C. M., Laurent, D., \& Vogel, C. M. (1996). Proper methodologies for psychological and sociological studies conducted via the internet. Behavior Research Methods, Instruments, \& Computers, 28, 186-191.

Hill, M. S. (2002). Examining objectification theory: Sexual objectification's link with self-objectification and moderation by sexual orientation and age in White women. Unpublished doctoral dissertation, The University of Akron.

Kashubeck-West, S., Mintz, L. B., \& Saunders, K. J. (2001). Assessment of eating disorders in women. The Counseling Psychologist, 29, 662694.

Kimmel, S. B., \& Mahalik, J. R. (2005). Body image concerns of gay men: The roles of minority stress and conformity to masculine norms. Journal of Counseling and Clinical Psychology, 73, 1185-1190. doi:10.1037/ 0022-006X.73.6.1185

Klonoff, E. A., \& Landrine, H. (1995). A measure of lifetime and recent sexist discrimination in women's lives. Psychology of Women Quarterly, 19, 439-470. doi:10.1111/j.1471-6402.1995.tb00086.x

Kozee, H. B., \& Tylka, T. L. (2007). A test of objectification theory with lesbian women. Psychology of Women Quarterly, 30, 348-357. doi: 10.1111/j.1471-6402.2006.00310.x

Kozee, H. B., Tylka, T. L., Augustus-Horvath, C. L., \& Denchik, A. (2007). Development and psychometric evaluation of the Interpersonal Sexual Objectification Scale. Psychology of Women Quarterly, 31, 176189. doi:10.1111/j.1471-6402.2007.00351.x

Lakkis, J., Ricciardelli, L. A., \& Williams, R. J. (1999). Roles of sexual orientation and gender-related traits in disordered eating. Sex Roles, 41, 1-16. doi:10.1023/A:1018829506907

Landrine, H., \& Klonoff, E. A. (1996). The schedule of racist events: A measure of racial discrimination and a study of its negative consequences. Journal of Black Psychology, 22, 144-165. doi:10.1177/ 00957984960222002

Lindberg, S. M., Grabe, S., \& Hyde, J. S. (2007). Gender, pubertal development, and peer sexual harassment predict objectified body consciousness in early adolescence. Journal of Research on Adolescence, 17, 723-742. doi:10.1111/j.1532-7795.2007.00544.x

Lindberg, S. M., Hyde, J. S., \& McKinley, N. M. (2006). A measure of objectified body consciousness for preadolescent and adolescent youth. Psychology of Women Quarterly, 30, 65-76. doi:10.1111/j.14716402.2006.00263.x

Lowery, S. E., Kurpius, S. E. R., Befort, C., Blanks, E. H., Sollenberger, S., Nicpon, M. F., \& Huser, L. (2005). Body image, self-esteem, and health-related behaviors among male and female first year college students. Journal of College Student Development, 46, 612-623. doi: 10.1353/csd.2005.0062

Mallinckrodt, B., Abraham, W. T., Wei, M., \& Russell, D. W. (2006). Advances in testing the statistical significance of mediation effects.
Journal of Counseling Psychology, 53, 372-378. doi:10.1037/00220167.53.3.372

Martins, Y., Tiggemann, M., \& Kirkbride, A. (2007). Those speedos become them: The role of self-objectification in gay and heterosexual men's body image. Personality and Social Psychology Bulletin, 33, 634-647. doi:10.1177/0146167206297403

McKinley, N. M. (1998). Gender differences in undergraduates' body esteem: The mediating effect of objectified body consciousness and actual/ideal weight discrepancy. Sex Roles, 39, 113-123. doi:10.1023/ A: 1018834001203

McKinley, N. M. (2006). Longitudinal gender differences in objectified body consciousness and weight-related attitudes and behaviors: Cultural and developmental contexts in the transition from college. Sex Roles, 54, 159-173. doi:10.1007/s11199-006-9335-1

McKinley, N. M., \& Hyde, J. S. (1996). The Objectified Body Consciousness Scale: Development and validation. Psychology of Women Quarterly, 20, 181-215. doi:10.1111/j.1471-6402.1996.tb00467.x

Meyer, I. H., \& Wilson, P. A. (2009). Sampling lesbian, gay, and bisexual populations. Journal of Counseling Pychology, 56, 23-31. doi:10.1037/ a0014587

Michalak, E. E., \& Szabo, A. (1998). Guidelines for internet research: An update. European Psychologist, 3, 70-75. doi:10.1027//1016-9040.3.1.70

Moradi, B., Dirks, D., \& Matteson, A. (2005). Roles of sexual objectification experiences and internalization of standards of beauty in eating disorder symptomatology: A test and extension of objectification theory. Journal of Counseling Psychology, 52, 420-428. doi:10.1037/00220167.52.3.420

Moradi, B., \& Huang, Y.-P. (2008). Objectification theory and psychology of women: A decade of advances and future directions. Psychology of Women Quarterly, 32, 377-398. doi:10.1111/j.1471-6402.2008.00452.x

Moradi, B., Mohr, J. J., Worthington, R. L., \& Fassinger, R. E. (2009). Counseling psychology research on sexual (orientation) minority issues: Conceptual and methodological challenges and opportunities. Journal of Counseling Psychology, 56, 5-22. doi:10.1037/a0014572

Morrison, M. A., Morrison, T. G., \& Sager, C. L. (2004). Does body satisfaction differ between gay men and lesbian women and heterosexual men and women? A meta-analytic review. Body Image, 1, 127-138. doi:10.1016/j.bodyim.2004.01.002

Morry, M. M., \& Staska, S. L. (2001). Magazine exposure: Internalization, self-objectification, eating attitudes, and body satisfaction in male and female university students. Canadian Journal of Behavioural Science, 33, 269-279. doi: $10.1037 / \mathrm{h} 0087148$

National Center for Health Statistics. (2007). Overweight, obesity, and healthy weight among persons 20 years of age and over, by sex, age, race and Hispanic origin, and poverty level: United States, 1960-1962 and through 2001-2004. Retrieved December 14 from http://www.cdc.gov/ nchs/data/hus/hus07.pdf\#074

Noll, S. M., \& Fredrickson, B. L. (1998). A mediational model linking self-objectification, body shame, and disordered eating. Psychology of Women Quarterly, 22, 623-636. doi:10.1111/j.1471-6402.1998.tb00181.x

Nosek, B. A., Banaji, M. R., \& Greenwald, A. G. (2002). E-Research: Ethics, security, design, and control in psychological research on the internet. Journal of Social Issues, 58, 161-176. doi:10.1111/15404560.00254

Petrie, T. A., \& Rogers, R. (2001). Extending the discussion of eating disorders to include men and athletes. The Counseling Psychologist, 29, 743-753. doi:10.1177/0011000001295006

Ponterotto, J. G., \& Ruckdeschel, D. E. (2007). An overview of coefficient alpha and a reliability matrix for estimating adequacy of internal consistency coefficients with psychological research measures. Perceptual and Motor Skills, 105, 997-1014. doi:10.2466/PMS.105.7.997-1014

Reilly, A., \& Rudd, N. A. (2006). Is internalized homonegativity related to body image? Family and Consumer Sciences Research Journal, 35, 58-73. doi:10.1177/1077727X06289430 
Riggle, E. D. B., Rostosky, S. S., \& Reedy, C. S. (2005). Online surveys for BGLT research: Issues and techniques. Journal of Homosexuality, 49, 1-21. doi:10.1300/J082v49n02_01

Rohlinger, D. A. (2002). Eroticizing men: Cultural influences on advertising and male objectification. Sex Roles, 46, 61-74. doi:10.1023/A: 1016575909173

Root, M. (2001). Future considerations in research on eating disorders. The Counseling Psychologist, 29, 754-762. doi:10.1177/0011000001295007

Russell, C. J., \& Keel, P. K. (2002). Homosexuality as a specific risk factor for eating disorders in men. International Journal of Eating Disorders, 31, 300-306. doi:10.1002/eat.10036

Sender, K. (1999). Selling sexual subjectivities: Audiences respond to the gay window advertising. Critical Studies in Mass Communication, 16, 172-196. doi:10.1080/15295039909367085

Serpa, J. G. (2004). A new measure of body dissatisfaction and its relation to self-objectification, eating disorders, and depression in gay and heterosexual men. Unpublished doctoral dissertation, Alliant International University.

Shrout, P. E., \& Bolger, N. (2002). Mediation in experimental and nonexperimental studies: New procedures and recommendation. Psychological Methods, 7, 422-445. doi:10.1037/1082-989X.7.4.422

Siever, M. D. (1994). Sexual orientation and gender as factors in socioculturally acquired vulnerability to body dissatisfaction and eating disorders. Journal of Consulting and Clinical Psychology, 62, 252-260. doi:10.1037/0022-006X.62.2.252

Silberstein, L. R., Mishkind, M. E., Striegel-Moore, R. H., Timko, C., \& Rodin, J. (1989). Men and their bodies: A comparison of homosexual and heterosexual men. Psychosomatic Medicine, 51, 337-346.

Stice, E. (2002). Risk and maintenance factors for eating pathology: A meta-analytic review. Psychological Bulletin, 128, 825-848. doi: 10.1037/0033-2909.128.5.825

Strelan, P., \& Hargreaves, D. (2005a). Reasons for exercise and body esteem: Men's responses to self-objectification. Sex Roles, 53, 495-503. doi:10.1007/s11199-005-7137-5

Strelan, P., \& Hargreaves, D. (2005b). Women who objectify other women: The vicious circle of objectification? Sex Roles, 52, 707-712. doi: 10.1007/s11199-005-3737-3

Strong, S. M., Williamson, D. A., Netemeyer, R. G., \& Geer, J. H. (2000) Eating disorder symptoms and concerns about body differ as a function of gender and sexual orientation. Journal of Social and Clinical Psychology, 19, 240-255.

Swim, J. K., Cohen, L. L., \& Hyers, L. L. (1998). Experiencing everyday prejudice and discrimination. In J. K. Swim \& C. Stangor (Eds.), Prejudice: The target's perspective. San Diego, CA: Academic Press.

Tabachnick, B. G., \& Fidell, L. S. (2001). Using multivariate statistics (4th ed.). New York, NY: Harper \& Row.

Thompson, J. K., \& Cafri, G. (2007). The muscular ideal: Psychological, social, and medical perspectives. Washington, DC: Springer. doi: 10.1037/11581-000

Tiggemann, M., \& Kuring, J. K. (2004). The role of body objectification in disordered eating and depressed mood. British Journal of Clinical Psychology, 43, 299-311. doi:10.1348/0144665031752925

Weston, R., \& Gore, P. A. (2006). A brief guide to structural equation modeling. The Counseling Psychologist, 34, 719-751. doi:10.1177/ 0011000006286345

Received March 17, 2009

Revision received January 5, 2010

Accepted January 12, 2010

\section{Call for Nominations: Emotion}

The Publications and Communications (P\&C) Board of the American Psychological Association has opened nominations for the editorship of the journal Emotion for the years 2012-2017. Elizabeth A. Phelps is the incumbent editor.

Candidates should be members of APA and should be available to start receiving manuscripts in early 2011 to prepare for issues published in 2012. Please note that the P\&C Board encourages participation by members of underrepresented groups in the publication process and would particularly welcome such nominees. Self-nominations are also encouraged. The search is being chaired by Norman Abeles, PhD.

Candidates should be nominated by accessing APA's EditorQuest site on the Web. Using your Web browser, go to http://editorquest.apa.org. On the Home menu on the left, find "Guests." Next, click on the link "Submit a Nomination," enter your nominee's information, and click "Submit."

Prepared statements of one page or less in support of a nominee can also be submitted by e-mail to Emnet Tesfaye, P\&C Board Search Liaison, at emnet@apa.org. 